\title{
Long-Term Prognosis after Recovery from Myocardial Infarction: A Community-Based Survey in Yamagata, Japan
}

\author{
Isao Kubota, Motoyuki Matsui, Hiroshi Ito*, Mikio Saito**, Koichi Yokoyama**, \\ Seiji YasumurA*** and Hitonobu ToMOIKE****
}

\begin{abstract}
Objective To assess the long-term prognosis after recovery from acute myocardial infarction (AMI) in the general population in Japan.

Patients and Methods Among the 575,000 inhabitants of the Yamagata metropolitan area, a total of 117 patients suffered from first their AMI from April to December 1993. Thirteen patients $(11 \%)$ died within four weeks after the onset. Of the remaining 104 patients, 101 (mean age, $69 \pm 12$ years) were followed for an average of $65 \pm 5$ months.

Results Twenty-seven of the 101 patients (27\%) died during the follow-up period. Compared with survivors, the patients who died were significantly older at the onset of AMI ( $74 \pm 12$ vs. $67 \pm 12$ years, $p<0.01)$. More diabetic patients than non-diabetic patients died ( 42 vs. $21 \%, p<0.05$ ) because of the higher frequency of non-cardiac deaths $(29$ vs. $11 \%, p<0.05)$. The total number of deaths of cardiac origin, including sudden deaths, was $11(40 \%)$ and was lower than the number of definite non-cardiac deaths $(n=15)$. The time from the onset of AMI to death was significantly shorter in cases of cardiac death than in cases of non-cardiac death (median, 16 vs. 45 months, $p<0.01$ ). Among non-cardiac deaths, deaths due to lung cancer and cerebral infarction were notable in men (standardized mortality ratio 278) and women (571), respectively.

Conclusion Non-cardiac death during long-term follow-up after AMI was more frequent than death of cardiac origin. Thus, preventive measures, including early treatment of complicating diseases, must be implemented to improve the long-term prognosis of patients with myocardial infarction.
\end{abstract}

(Internal Medicine 40: 589-593, 2001)

Key words: cardiac death, non-cardiac death, diabetes mellitus

\section{Introduction}

In contrast to the data available on Western populations, little information is available on the prognosis of Japanese subjects after an acute myocardial infarction (AMI). Several reports have been published by researchers of hospitals that specialize in cardiology (1-4). However, it is unclear whether the results of such studies represent the average outcome for AMI patients in Japan. Differences in patient profiles among hospitals in various categories are well known all over the world. Mortality as a result of AMI has decreased over the past 20 years and improvements in treatment might favor patients admitted to hospitals with very modern facilities. To minimize the bias that is based on the sophistication of available treatments at various hospitals, the prognosis of patients after heart attacks should be surveyed in a community-based population. Thus, this study was designed to clarify the long-term prognosis of patients after AMI in a regional community in Japan.

\section{Methods}

We designed a community-based, annual survey of AMI in Yamagata Prefecture (census population in 1993, 1,250,000) $(5,6)$. We recently documented the status of the short-term prognosis after AMI in this same district (5). To investigate the long-term prognosis after AMI in the Yamagata area, patients who were registered from April to December 1993 were enrolled in our survey. We followed the outcome of these patients, accumulating coded information from attending and/or family physicians.

A total of 117 patients ( 73 men and 44 women, aged $69 \pm 12$ years) suffered from first AMI in the Yamagata metropolitan area (census population in 1993, 575,000) from April to December 1993. The diagnosis of AMI was based on the "definite criteria of AMI" that were defined by the WHO MONICA Project (7). In brief, the criteria for diagnosis of AMI were: 1) a definite ECG; 2) a probable ECG and abnormal enzyme levels; 3) typical symptoms and abnormal enzyme levels; or 4)

From Okitama Public General Hospital, *Oguni Town Hospital, **Yamagata Prefectural Central Hospital, ***the Department of Public Health and ****the First Department of Internal Medicine, Yamagata University School of Medicine, Yamagata

Received for publication June 19, 2000; Accepted for publication January 19, 2001

Reprint requests should be addressed to Dr. Isao Kubota, the Department of Internal Medicine, Okitama Public General Hospital, 2000 Nishi-Ohtsuka, Kawanishimachi, Yamagata 992-0601 
death that appeared to the naked eye to be due to fresh myocardial infarction and/or recent coronary occlusion found at necropsy.

Thirteen patients (11\%) died within four weeks after the onset of AMI. Nine (69\%) of these 13 patients suffered from severe heart failure when they arrived at the hospital (Killip class III or IV). Death was of cardiac origin in all cases (heart failure, 9 cases; cardiac rupture, 2 cases; and malignant ventricular arrhythmia, 2 cases). Of the remaining 104 patients, 101 patients (97\%; mean age, $69 \pm 12$ years) were followed for an average of $65 \pm 5$ months. Sixty-six $(65 \%)$ were men $(66 \pm 11$ years) and $35(35 \%)$ were women ( $74 \pm 12$ years). The background of these patients is summarized in Table 1. The clinical variables selected for our analysis of long-term prognosis were age, sex, hypertension, diabetes mellitus, hyperlipidemia (total cholesterol $\geq 220 \mathrm{mg} / \mathrm{dl}$ ), smoking habit just before the onset of AMI and admission Killip class III or IV. Variables with

Table 1. Background of 101 Patients Studied

\begin{tabular}{lcc}
\hline \multicolumn{2}{l}{ Age (years; mean \pm SD) } & $69 \pm 12$ \\
\hline Sex men & $(+)$ & $64(63 \%)$ \\
women & $(-)$ & 37 \\
Hypertension & $(+)$ & $53(55 \%)$ \\
& $(-)$ & 43 \\
Diabetes mellitus & $(+)$ & $25(26 \%)$ \\
& $(-)$ & 72 \\
Hyperlipidemia & $(+)$ & $24(27 \%)$ \\
& $(-)$ & 64 \\
Current smoking & $(+)$ & $44(44 \%)$ \\
Killip III or IV & $(-)$ & 46 \\
& $(+)$ & $9(9 \%)$ \\
& $(-)$ & 92 \\
\hline
\end{tabular}

Patients without available data were excluded. regard to the size of MI, severity of coronary artery disease or therapies were not included because of the lack of data.

Using the mortality rates for 1995 for all residents in Yamagata, we calculated the number of expected deaths in an age- and sex-adjusted 'control' group of the same sample size during the same follow-up period. In this analysis, we computed the numbers of total deaths, cardiac deaths [in the 10th revision of the International Statistical Classification of Diseases and Related Health Problems (ICD-10) (8), code 09200], deaths due to cerebrovascular accident (apoplexy; ICD-10 code 09300) and deaths by lung cancer (ICD-10 code 02108) in the 'control' group. The standardized mortality ratio (SMR) was defined as (the number of observed deaths) / (the number of expected deaths in the 'control' group) $\times 100$.

Data are expressed as mean \pm SD. Differences between groups were analyzed by an unpaired t-test, by chi-squared analysis or by Mann-Whitney's U-test. A value of $\mathrm{p}<0.05$ was considered to indicate a statistically significant difference.

\section{Results}

Twenty-seven patients (27\%) died during the follow-up period; 14 were men (mean age at death $73 \pm 11$ years) and 13 were women ( $80 \pm 11$ years). Compared with survivors, the patients who died were significantly older at the onset of AMI ( $74 \pm 12$ vs. $67 \pm 12$ years, $p<0.01$ ). The causes of death were sudden death in six cases, repeated AMI in three, heart failure in two, malignant neoplasm in seven, apoplexy in six, pneumonia in two and undetermined in one (Table 2). Among noncardiac deaths, deaths due to lung cancer and cerebral infarction were dominant in men $(n=4)$ and women $(n=5)$, respectively. The total number of deaths of cardiac origin, including sudden death, was $11(40 \%)$, which was less than the number of definite non-cardiac death $(n=15)$. Figure 1 shows the times from the onset of AMI to death for cases of cardiac and non-

Table 2. Causes of Death and Times from Onset of AMI to Death

\begin{tabular}{|c|c|c|c|c|}
\hline & \multicolumn{3}{|c|}{ Number of patients } & \multirow[b]{2}{*}{ Time (months) } \\
\hline & Total & Men & Women & \\
\hline Cardiac death & 11 & 7 & 4 & 16 (median value) \\
\hline Sudden death & 6 & 3 & 3 & $5,8,16,24,34,35$ \\
\hline Repeated AMI & 3 & 2 & 1 & $2,16,22$ \\
\hline Heart failure & 2 & 2 & 0 & 2,10 \\
\hline Non-cardiac death & 15 & 7 & 8 & $45^{*}$ (median value) \\
\hline Malignant neoplasm & 7 & $5^{\mathrm{a}}$ & $2^{b}$ & $16,23,30,45,46,49,58$ \\
\hline Apoplexy & 6 & $1^{\mathrm{c}}$ & $5^{\mathrm{d}}$ & $26,44,46,61,64,67$ \\
\hline Pneumonia & 2 & $1^{\mathrm{e}}$ & $1^{\mathrm{f}}$ & 4,4 \\
\hline Unknown & 1 & 0 & 1 & 24 \\
\hline Total & 27 & 14 & 13 & 24 (median value) \\
\hline
\end{tabular}

AMI: acute myocardial infarction. a: Lung cancer, 4; chronic myeloblastic leukemia, 1. b: Rectal cancer, 1; gastric cancer, 1. c: Cerebral infarction. d: Cerebral infarction, 4; cerebral hemorrhage, 1. e: Interstitial pneumonia. f: Acute bacterial pneumonia. $* \mathrm{p}<0.01$ vs. cardiac death. 


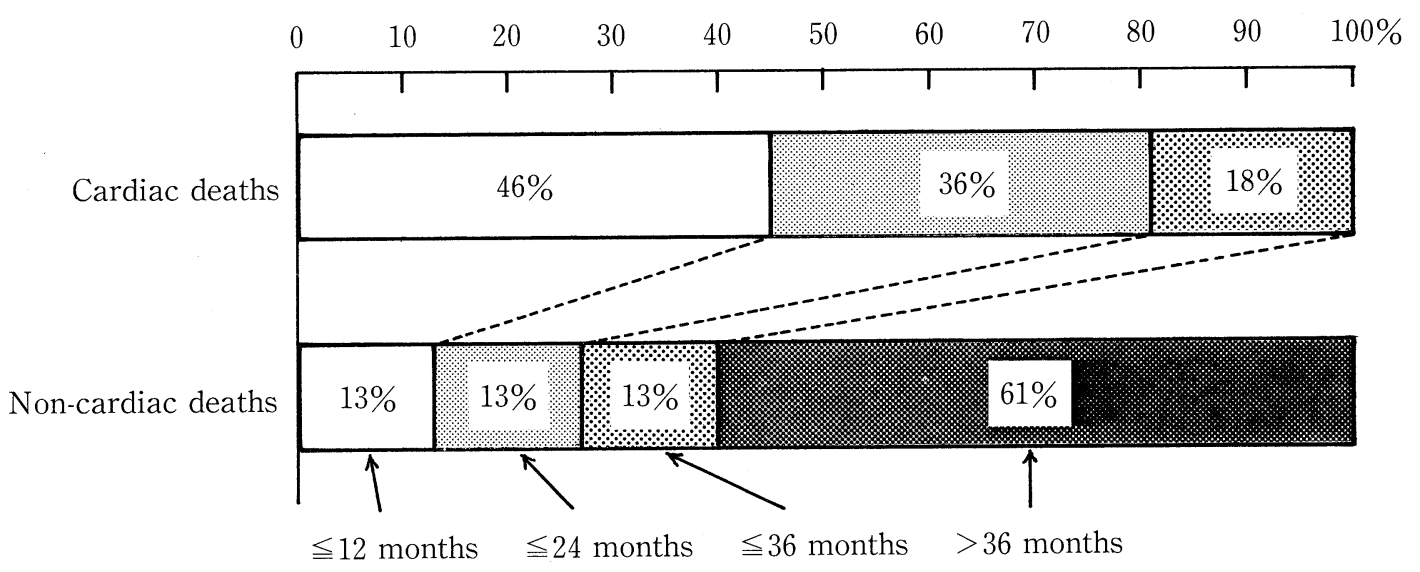

Figure 1. Differences in the time from the onset of acute myocardial infarction to death between cardiac deaths and non-cardiac deaths.

cardiac death. The time from AMI to death was significantly shorter in cases of cardiac death than in cases of non-cardiac death (median, 16 vs. 45 months, $\mathrm{p}<0.01$ ). This difference was not due to the difference of patients' age since the mean age of the two groups was identical (74 years, Table 3 ). Unlike cardiac deaths, more than half of non-cardiac deaths occurred more than 36 months after AMI. There were no cardiac deaths among the patients who survived for more than 36 months in the present study population.

Table 3 summarizes the effects of risk factors on the total, cardiac and non-cardiac deaths. More diabetic patients than non-diabetic patients died ( 42 vs. $21 \%, \mathrm{p}<0.05$ ) because of the higher frequency of non-cardiac deaths ( 29 vs. $11 \%, \mathrm{p}<0.05)$. Other factors such as the distinction of sex, the presence of hypertension or hyperlipidemia, smoking habits just before AMI or admission Killip class III or IV did not have a significant influence on the total, cardiac or non-cardiac deaths.

Table 4 shows the numbers of observed deaths in our patient group and expected deaths in the age- and sex-adjusted 'control' group. The incidence of total deaths (SMR 197), as

Table 4. Numbers of Observed and Expected Deaths

\begin{tabular}{lccc}
\hline & Observed & Expected & SMR \\
\hline Total death & 27 & $13.7^{* *}$ & 197 \\
Cardiac death & 11 & $2.4^{* *}$ & 458 \\
Non-cardiac death & 15 & 11.3 & 133 \\
Apoplexy (women) & 5 & $1.8^{* *}$ & 278 \\
Lung cancer (men) & 4 & $0.7^{* *}$ & 571 \\
\hline
\end{tabular}

${ }^{* *} \mathrm{p}<0.01$. SMR: Standardized mortality ratio.

Table 3. Risk Factors of Total, Cardiac and Non-cardiac Deaths

\begin{tabular}{|c|c|c|c|c|c|}
\hline & & $\mathrm{n}$ & $\begin{array}{l}\text { Total } \\
\text { death }\end{array}$ & $\begin{array}{l}\text { Cardiac } \\
\text { death }\end{array}$ & $\begin{array}{c}\text { Non-cardiac } \\
\text { death }\end{array}$ \\
\hline \multicolumn{2}{|c|}{ Age (years; mean \pm SD) } & 100 & $74 \pm 12$ & $74 \pm 13$ & $74 \pm 11$ \\
\hline Sex men & & 64 & $14(22 \%)$ & $7(11 \%)$ & $7(11 \%)$ \\
\hline women & & 36 & $16(33 \%)$ & $4(11 \%)$ & $8(22 \%)$ \\
\hline \multirow{2}{*}{ Hypertension } & $(+)$ & 52 & $16(31 \%)$ & $6(12 \%)$ & $10(19 \%)$ \\
\hline & $(-)$ & 43 & $8(19 \%)$ & $4(9 \%)$ & $4(9 \%)$ \\
\hline \multirow[t]{2}{*}{ Diabetes mellitus } & $(+)$ & 24 & $10(42 \%)^{*}$ & $3(13 \%)$ & $7(29 \%)^{*}$ \\
\hline & $(-)$ & 72 & $15(21 \%)$ & $7(10 \%)$ & $8(11 \%)$ \\
\hline \multirow[t]{2}{*}{ Hyperlipidemia } & $(+)$ & 24 & $3(13 \%)$ & $2(8 \%)$ & $1(4 \%)$ \\
\hline & $(-)$ & 63 & $17(27 \%)$ & $7(11 \%)$ & $10(16 \%)$ \\
\hline \multirow[t]{2}{*}{ Current smoking } & $(+)$ & 44 & $10(23 \%)$ & $6(14 \%)$ & $4(9 \%)$ \\
\hline & $(-)$ & 46 & $14(30 \%)$ & $4(9 \%)$ & $10(22 \%)$ \\
\hline \multirow[t]{2}{*}{ Killip III or IV } & $(+)$ & 9 & $3(33 \%)$ & $1(11 \%)$ & $2(22 \%)$ \\
\hline & $(-)$ & 91 & $23(25 \%)$ & $10(11 \%)$ & $13(14 \%)$ \\
\hline
\end{tabular}

One patient whose cause of death was unknown was excluded from the analysis. In the analysis of each factor, patients without available data were excluded. ${ }^{*} \mathrm{p}<0.05$. 
well as cardiac deaths (SMR 458), was significantly higher in the present study group than in the 'control' group. Among non-cardiac deaths, the incidence of lung cancer in men (SMR 571) and that of apoplexy in women (SMR 278) were significantly higher in the study group than in the 'control' group.

\section{Discussion}

The mortality during a mean follow-up period of 65 months in the present study was $27 \%$. This value is higher than values in previous reports from hospitals that specialize in cardiology in Japan (1-4), for example, 9.6\% during a mean follow-up period of 110 months [Ogawa et al (1)] and $19.1 \%$ in a 5-year follow-up study [Saito et al (2)]. It is likely that our higher mortality rate was due mainly to the higher mean age of our study population (69 years), as compared with those in previous studies (54-62 years) (1-4). The difference in mean age was probably due to the design of our study, which was aimed at registering every AMI in Yamagata Prefecture in the chosen time period. In addition, the higher ratio of people of 65 years of age or older in Yamagata (21\%, the third highest percentage in 42 prefectures in Japan, according the 1995 census) is likely to have been another factor that raised the mean age of our study population.

The present study confirmed the importance of age at the onset of myocardial infarction (9-12) and of complications due to diabetes mellitus (9-11) as prognostic determinants in longterm follow-up. In addition, we demonstrated that the higher mortality of diabetic patients was due mainly to the higher frequency of non-cardiac deaths. Admission Killip class III or IV was not correlated with long-term survival, although Killip class III or IV has been repeatedly confirmed to be a strong predictor of poor prognosis $(10,13)$. Further studies are required, using larger numbers of patients, to identify with greater accuracy the predictors of long-term mortality in Japan.

In a previous report on short-term (four-week) prognosis, we demonstrated that the largest number of deaths occurred within 24 hours, and more than half of all deaths occurred within 72 hours after the onset of AMI (5). We also found, during the long-term follow-up study, that the frequency of cardiac deaths but not that of non-cardiac deaths tended to decrease with the passage of time. As a result, non-cardiac deaths were more frequent than deaths of cardiac origin in our study population. In Western populations $(14,15)$ and in a migrant Japanese population in Honolulu (10), cardiac deaths have been reported to be more frequent than non-cardiac deaths, not only during shortterm but also during long-term follow-up. In some studies in Japan $(1,3)$, by contrast, non-cardiac deaths were reported more frequently than cardiac deaths during long-term follow-up. However, the clinical importance of non-cardiac deaths in patients after AMI has not been stressed previously. Therefore, it seems important now to pay attention to non-cardiac diseases during long-term follow-up.

It is quite natural that the number of cardiac deaths should have been much larger than the expected number in the "control' group. We also found that the number of non-cardiac deaths tended to be larger than that in the 'control' group. The higher incidence of deaths due to apoplexy in women suggests the presence of advanced arteriosclerosis or latent cerebrovascular damage among feminine patients. It is well known that the habit of smoking increases not only the risk of AMI but also the occurrence of lung cancer. In fact, $71 \%$ of male patients in this study were current smokers. However, two of the 4 patients who died of lung cancer were non-smokers. Thus, no contribution of smoking to increased risk of lung cancer in male AMI patients was shown in the present study.

At the time of patient registration (1993), we did not collect data on reperfusion therapy. The percentage of patients receiving reperfusion therapy is increasing in Yamagata (43\% in 1994 vs. $70 \%$ in 1998, unpublished observation) as it is also in USA $(17,18)$. Since reperfusion therapy is considered to reduce the likelihood of cardiac death during long-term $(11,16)$, as well as short-term follow-up $(5,6)$, the ratio of non-cardiac deaths to cardiac deaths will likely further increase with the widespread use of this therapy.

In conclusion, we have characterized the long-term prognosis after AMI for unselected patients in Yamagata, Japan, on the basis of a community-wide survey. We found that non-cardiac deaths were more frequent than deaths of cardiac origin, an indication of the importance of prevention and early treatment of complicating diseases in efforts to improve the quality of life and the well-being of patients after AMI.

\section{References}

1) Ogawa H, Kawana M, Tamura K, Kimata S, Hosoda S. Long-term prognosis of medically treated patients with acute myocardial infarction and one-vessel coronary artery disease. Am J Cardiol 73: 158-163, 1994.

2) Saito M, Fukami K, Hiramori K, et al. Long-term prognosis of patients with acute myocardial infarction: Is mortality and morbidity as low as the incidence of ischemic heart disease in Japan? Am Heart J 113: 891-897, 1987.

3) Kanzaki H, Miyazaki S, Noguchi T, et al. Influence of calcium antagonists on long-term survival of patients treated with coronary angioplasty. Jpn Heart J 40: 11-21, 1999.

4) Hosoda S, Kimata S, Tamura K, et al. Follow-up of 2,733 patients with myocardial infarction. Jpn Circ J 59: 121-129, 1995.

5) Kubota I, Ito H, Yokoyama K, Yasumura S, Tomoike H. Early mortality after acute myocardial infarction. Observational study in Yamagata, 19931995. Jpn Circ J 62: 414-418, 1998.

6) Ito H, Kubota I, Yokoyama K, Yasumura S, Tomoike H. Angioplasty but not thrombolysis improves short-term mortality of acute myocardial infarction. A multicenter survey in Yamagata, Japan. Jpn Heart J 40: $383-$ 389, 1999.

7) Tunstall-Pedoe H, Kuulasmaa K, Amouyel P, Arveiler D, Rajakangas AM, Pajak A. WHO MONICA Project. Myocardial infarction and coronary deaths in the World Health Organization MONICA Project. Registration procedures, event rates, and case-fatality rates in 38 populations from 21 countries in 4 continents. Circulation 90: 583-612, 1994.

8) The International Statistical Classification of Diseases and Related Health Problems, 10th Revision, Volume 1, World Health Organization Distribution and Sales, Geneva, 1992.

9) Martin CA, Thompson PL, Armstrong BK, Hobbs MST, de Klerk N. Longterm prognosis after recovery from myocardial infarction. A nine year follow-up of the Perth Coronary Register. Circulation 68: 961-969, 1983.

10) Yano K, Grove JS, Reed DM, Chun HM. Determinants of the prognosis after a first myocardial infarction in a migrant Japanese population. The 


\section{Long-term Prognosis after MI in Japan}

Honolulu Heart Program. Circulation 88: 2582-2595, 1993.

11) Gottlieb $S$, Boyko V, Harpaz D, et al. Long-term (three-year) prognosis of patients treated with reperfusion or conservatively after acute myocardial infarction. J Am Coll Cardiol 34: 70-82, 1999.

12) Goldberg RJ, Gore JM, Gurwitz JH, et al. The impact of age on the incidence and prognosis of initial acute myocardial infarction. The Worcester Heart Attack Study. Am Heart J 117: 543-549, 1989.

13) Jacobs DR Jr, Kroenke C, Crow R, et al. PREDICT: A simple risk score for clinical severity and long-term prognosis after hospitalization for acute myocardial infarction or unstable angina. The Minnesota Heart Survey. Circulation 100: 599-607, 1999.

14) Buchwald H, Varco RL, Matts JP, et al. Effect of partial ileal bypass surgery on mortality and morbidity from coronary heart disease in patients with hypercholesterolemia. Report of the program on the surgical control of the hyperlipidemia (PORSH). N Eng J Med 323: 946-955, 1990.
15) Scandinavian Simvastatin Survival Study Group. Randomised trial of cholesterol lowering in 4444 patients with coronary heart disease: the Scandinavian Simvastatin Survival Study (4S). Lancet 344: 1383-1389, 1994.

16) Lenderink T, Simoons ML, Van Es GA, Van de Werf, Verstraete M, Arnold AER, and The European Cooperative Study Group. Benefit of thrombolytic therapy is sustained throughout five years and is related to TIMI perfusion grade 3 but not grade 2 flow at discharge. Circulation 92: 11101116, 1995.

17) Rogers WJ, Bowlby LJ, Chandra NC, et al. Treatment of myocardial infarction in the United States (1990 to 1993). Observations from the National Registry of Myocardial Infarction. Circulation 90: 2103-2114, 1994.

18) Barron HV, Bowlby LJ, Breen T, et al. Use of reperfusion therapy for acute myocardial infarction in the United States: data from the National Registry of Myocardial Infarction 2. Circulation 97: 1150-1156, 1998. 